\title{
Ex Hacienda de Montoya: El valor de los materiales y sus sistemas constructivos para su conservación
}

\author{
Ex Hacienda de Montoya: The value of materials and their construction \\ systems for their conservation
}

\author{
Ex Hacienda de Montoya: O valor dos materiais e seus sistemas \\ construtivos para sua conservação
}

Rosa María López Oliver Farías

Arquitecta, M.Sc. Arquitectura, Ph.D en Arquitectura en

el Área de Restauración de Sitios y Monumentos

Universidad Anáhuac de Oaxaca. México.

rosalopezo@anahuac.mx

(D) https://orcid.org/0000-0002-6155-2808

Recibido: septiembre 6 de 2020

Aceptado: octubre 20 de 2020

Publicado: octubre 30 de 2020

\section{RESUMEN}

El objetivo de este trabajo de investigación es recuperar el valor de los materiales con los que fue edificada la ex Hacienda de Montoya, ubicada en la capital Oaxaqueña. Los materiales que se utilizaron para erigir cada área estaban en función de la persona que lo habitaba. El material cumplía una función constructiva, pero también una escala de valor dentro de la estructura social hacendaria. Dichos materiales básicos han demostrado su eficacia a lo largo de los años. Promover su restauración y dar vida a estos espacios, sería una forma de que los materiales y sistemas constructivos sean valorados.

Palabras Clave: Sistemas Constructivos; Oaxaca; materiales; valoración arquitectónica; Hacienda.

\section{ABSTRACT}

The objective of this research work is to recover the value of the materials with which the Ex Hacienda de Montoya was built, located in the capital of Oaxaca. The materials that were used to build each area were based on the person who inhabited it. The material fulfilled a constructive function, but also a scale of value within the financial social structure. These basic materials have proven themselves over the years. Promoting their restoration and giving life to these spaces would be a way for the materials and construction systems to be valued.

Keywords: Constructive Systems; Oaxaca; materials; architectural assessment; Hacienda. 


\section{RESUMO}

O objetivo deste trabalho de pesquisa é recuperar o valor dos materiais com os quais foi construída a ex Hacienda de Montoya, localizada na capital Oaxaca. Os materiais usados para construir cada área foram baseados nas pessoas que as habitavam. O material cumpria uma função construtiva, mas também uma escala de valor dentro da estrutura social financeira. Esses materiais básicos foram comprovados ao longo dos anos. Promover a sua restauração e dar vida a estes espaços seria uma forma de valorizar os materiais e sistemas construtivos.

Palavras-chave: Sistemas construtivos; Oaxaca; materiais; avaliação arquitetônica; Hacienda.

\section{INTRODUCCIÓN}

Las Haciendas del Virreinato de la Nueva España fueron espacios creados para ejercer una actividad económica, siendo algunos territorios muy extensos; en Oaxaca fueron un tanto diferentes en cuanto a sus dimensiones, sin embargo, no dejan de ser importantes. Para comprender estas actividades hacendarias en particular la ex Hacienda de Montoya, fue importante profundizar en su historia, y para lograrlo fue necesario recurrir a la búsqueda de documentos inéditos e históricos en diversos archivos locales, nacionales e internacionales, en el que se abordaron ampliamente, pues el conocer su historiografía le da el valor que se merece particularmente esta edificación.

Es importante partir del origen y evolución de las Haciendas, para comprender cómo es que surgen, cómo se desarrollan, cuál es su vida útil y como prevalecen algunas hasta nuestros días. De ahí la importancia en este tema. Como consecuencia de la conquista española, la Nueva España, convertida en virreinato, se vio envuelta en un sin número de drásticos cambios, los cuales, sin lugar a dudas, vinieron a transformar, inevitablemente el modo de vida de los habitantes de este territorio. Uno de los cambios quizá más significativos fue el del sistema de la tenencia de la tierra, el cual pasó a ser determinado, en su totalidad, por la Corona Española la que, con el propósito de fomentar entre los españoles su estancia en el lugar, la Corona comenzó a repartir entre sus soldados de más alto rango y entre uno que otro aventurero de la nobleza, mercedes y encomiendas de tierra para el establecimiento de estancias ganaderas y huertas, así como de casas-habitación. Estas encomiendas llegaron a convertirse con el tiempo y por medio de la adquisición legal, en unos casos, y a través de la apropiación arbitraria, en otros, en una poderosa unidad socio-económica que vendría a jugar un papel de suma importancia en la historia rural del México colonial: La Hacienda.

Es importante explicar cómo es que estaban conformadas las Haciendas, para poder comprender la diferencia que había con otras Haciendas en el norte del país. Partiremos explicando, primero, qué significa la palabra Hacienda: François Chevalier (1999, p.378) en su libro: "La formación de latifundios en México" es bastante explícito. Lo que nos comenta el autor, haciendo un estudio muy acertado: "la palabra Hacienda había designado cualquier clase de bienes bajo el sol, muebles o inmuebles", es decir, se hablaba de Haciendas de ovejas, que cambiaban de lugar; se mencionan las Haciendas que poseían los indios, refiriéndose a los jacales, milpas y pertenencias; las Haciendas de minas, por ubicarse en lugares prósperos en la extracción de algún mineral o piedras preciosas; también Haciendas de labor y ganados, que en particular en Oaxaca es un término bastante utilizado, por mencionar algunas.

Este término fue evolucionando con el tiempo, pero no fue sino hasta el siglo XVIII en que se considera la época de oro de las Haciendas mexicanas, y que dicho significado llega a cobrar un valor e importancia considerándose la Arquitectura como el valor preponderante en el funcionamiento de la actividad social y económica. "En cada propiedad, los gañanes o peones representaron entonces un verdadero capital, lo cual contribuye quizá a explicar la fortuna de la palabra Hacienda" (Chevalier, 1999, p.380).

La Hacienda es un complejo socio-económico autosuficiente en la mayoría de los casos, que se encontraba formado por un núcleo espacial denominado Casco o Casa Grande, en la que vivía el hacendado con toda su familia; además, existían otras casas más modestas, destinadas al personal de confianza de la Hacienda, tales como el 
administrador (o tenedor de libros), el mayordomo, y algunos capataces. También existía una capilla en la que se ofrecían los servicios religiosos a todos los habitantes de la propiedad. Sus áreas de trabajo y producción como las trojes y las eras para el almacenamiento y la molienda de los granos, respectivamente, así como los establos para los animales (Taylor, 1998, p.157). También un poco más retirado, pero dentro de la finca, se ubicaban otro tipo de viviendas más humildes; eran las chozas hechas de piedra y bajareque que habitaban los peones acasillados, y eran así llamados, porque como pago de su salario recibían una casa donde vivir. "No puede faltar la famosa tienda de raya, en la que se vendían los productos básicos para los peones, y en donde estos lo pagaban mediante trabajos que realizaban en la Hacienda; estos productos se adelantaban al peón a cuenta de sus jornales, que así rara vez eran pagados en una mínima parte en moneda." (García G, 2011, p. 2)

Con la tienda de raya de alguna manera el beneficiado era el patrón, ya que las deudas contraídas para los peones se transmitían a sus hijos, por lo que el peón quedaba endeudado y por esta situación no podían abandonar la Hacienda. A diferencia de otras regiones de la Nueva España, donde las Haciendas prosperaron muchísimo hasta ser dueñas de extensiones inmensas, las del valle de Oaxaca eran la excepción. En esta región los descendientes de la antigua nobleza indígena, los llamados caciques, lograron conservar sus tierras y algunas de las fincas más grandes del valle eran de ellos, tal como sucedió con la ex Hacienda de Montoya. Aunque sin trabajadores que las sembraran, muchos terminaron por arrendarlas a los criollos, dueños de otras grandes propiedades y vecinos de Antequera. Los Dominicos y otras órdenes religiosas, como los Jesuitas, los Carmelitas y los Agustinos, también fueron importantes poseedores de tierras.

Las Haciendas en el Valle de Oaxaca fueron generalmente pequeñas, fragmentadas y tuvieron tanta o menor importancia que los numerosos ranchos y labores en donde se concentró el verdadero domino español de la propiedad. (Fernández, Enfield \& Ohara, 2004, p.140). Otra definición establece que el término Hacienda se relaciona con más frecuencia con las inmensas propiedades rurales del norte de México. "Las sugerencias van de 800 a 8,000 hectáreas. Muchas propiedades del Valle denominadas Haciendas en los registros coloniales, no tenían todas estas características. El tamaño de las Haciendas del Valle era muy variable. La mayoría de las 41 Haciendas registradas para 1643 , consistían en una estancia y unos cuantos terrenos de tierra para cultivo, muy lejos del mínimo de 8,000 hectáreas que propone Helen Phipps." (Taylor,1998, p.153).

Sobre la Hacienda que nos ocupa, podemos establecer que es una construcción del siglo XVII; estaba compuesta de un vasto territorio que fue creciendo conforme al cambio que tuvo de varios propietarios. Fue sin duda una de las más importantes para la propia ciudad, ya que de ella se abastecía de la producción que tenía. Se tienen datos documentados donde, para 1638, se da una autorización para matar cuatro mil cabezas de ganado cabrío. Algunos autores establecen que la Hacienda, arquitectónicamente hablando, estaba construida por una serie de edificios, mismos que servían para llevar a cabo diferentes actividades. Al conjunto de todos estos espacios arquitectónicos generalmente se le conoce como casco de la Hacienda. A partir del siglo XVII, la Hacienda constituyó, en palabras de Terán Bonilla (1998), una unidad productiva con una organización compleja, con unas características estructurales muy concretas. Básicamente, se presentan tres tipos de Haciendas, en función de la disposición de los edificios que las forman:

a) Haciendas cuyos edificios forman una unidad, es decir, que están integrados entre sí. Generalmente agrupados en torno a un patio, al que daban la casa principal, así como las áreas administrativas, las trojes y tinacales. Por lo usual, incluían una capilla, con acceso directo desde el patio. Las casas de los trabajadores, se situaban fuera de este núcleo principal.

b) Haciendas conformadas por edificios dispersos. Era frecuente que el área ocupada por los mismos se delimitara mediante una tapia perimetral, en la que se abría un portón con zaguán, para controlar las entradas y salidas. Al conjunto, se le denomina casco de la Hacienda.

c) Haciendas mixtas. Es decir, que poseen un conjunto agrupado de construcciones principales y, a la vez, edificios aislados del mismo. (Nickel, 1978, pp. 9-10)

Algunas Haciendas famosas en el valle de Oaxaca, que sobresalieron en aquella época, fueron: Xaagá, El Rosario, San José, El Vergel, Santo Domingo Buenavista, Hacienda Blanca, Los Molinos de Lazo y la Hacienda de Montoya. Ubicándose en el 
tipo de Hacienda cuyo edificio forma una unidad, donde todas sus áreas y actividades convergen a un patio central, que incluye una capilla, mientras que las casas de los peones se encontraban a su alrededor formando una pequeña villa. Con esto podemos definir los espacios arquitectónicos que las conforman, quedando su distribución como aparece en la siguiente Figura 1.

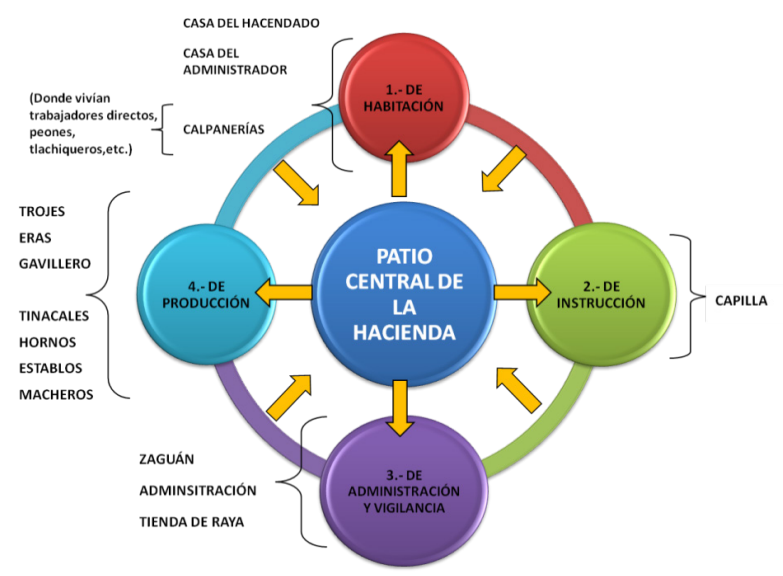

Figura 1. Espacios arquitectónicos de la ex Hacienda de Montoya. Fuente: Elaborado por la autora.

De acuerdo con la Figura anterior, el Patio Central es el eje principal del conjunto hacendario; cumple con un modelo de articulación entre espacios interiores y exteriores que se vinculan entre sí, con los cuatro espacios arquitectónicos más importantes de habitación, instrucción, administración-vigilancia, y producción. Su distribución responde a una organización lógica, en función del uso al que estaban destinados. Este partido arquitectónico hacendario tiene una relación directa sobre la función, los materiales y los sistemas constructivos, estableciendo una jerarquía social-arquitectónica.

Por otro lado, cabe señalar que, en el resto del actual estado de Oaxaca, la propia orografía impidió que prosperaran las Haciendas, pero hay que reconocer el gran esfuerzo de la comunidad por retener y cuidar sus tierras. Las autoridades de los pueblos oaxaqueños aprendieron a utilizar las Leyes de Indias realizando frecuentes viajes a la Ciudad de México, para defender con constancias sus derechos sobre su tierra y, gracias a eso, tenemos valiosos documentos que lo confirman.

El estudioso A. René Barbosa-Ramírez (1995) en su libro: "La Estructura Económica de la Nueva España (1519-1810)" nos comenta cómo la estructura social se encontraba conformada y señala: "La sociedad colonial es una economía jerarquizada, heterogénea, con una especialización de trabajo en correspondencia con la especialización racial. También refiere algo muy importante acerca de la jerarquización de los asentamientos, estableciendo que las ciudades corresponden a una jerarquización en el campo, en dónde el régimen de propiedad de tierra, con sus grandes explotaciones eclesiásticas con sus diversas inmunidades, reproducían la jerarquización que se producía hasta en los gremios y cofradías que provocaba una estratificación de los oficios en la que predominaba el maestro español." (Barbosa, 1995, p. 243).

Con esto, podemos establecer una jerarquía espacial, de acuerdo con dicha organización laboral, en donde los materiales y sistemas constructivos que se emplearon en estas edificaciones responden a un espacio-formal, siendo este determinante en su dimensión, tal como se muestra en la Figura 2.

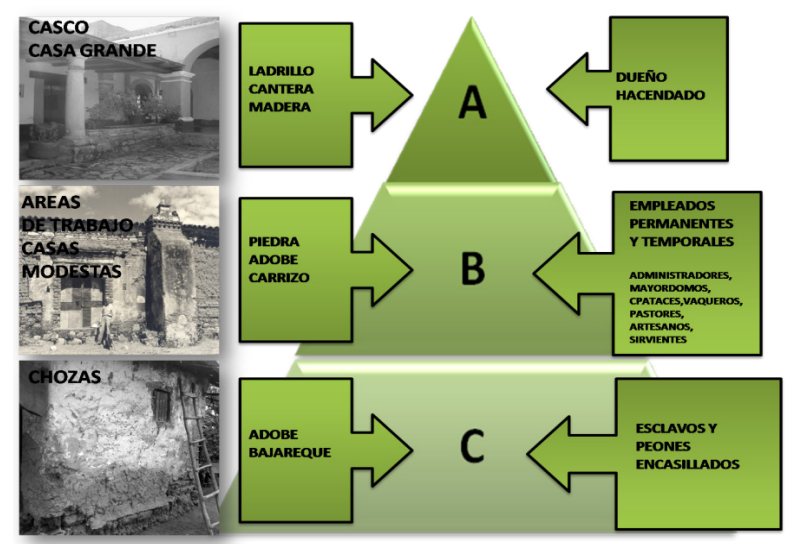

Figura 2. Organización laboral de las Haciendas. Socialarquitectónico.

Fuente: Elaborado por la autora.

\section{METODOLOGÍA}

El método de este trabajo de investigación corresponde a una historiografía, con base en el método de investigación deductivo que inicia en un marco histórico general para llegar al particular, en este caso a la ex Hacienda de Montoya en Oaxaca.

En el transcurso de este tema en el que se generan diversos documentos históricos, que gracias a su buen estado de conservación se han podido consultar y que bien vale la pena mencionar, las colecciones documentales de diferentes instituciones tantos gubernamentales, en algunos 
casos eclesiásticos, académicos y personales, en el que es necesario mencionarlos con la finalidad de que puedan ser hallados y consultados para futuras investigaciones. El procedimiento de esta investigación se llevó a cabo de la siguiente manera: la primera, histórica, y la segunda, referida a la investigación de campo.

a). Investigación Histórica y Documental: Se tomaron en cuenta los documentos de primera mano y para esto se visitaron los archivos del estado y de la Ciudad de México. En el caso de las Haciendas que tengan un dueño particular, los archivos propios fueron de mucha utilidad, en el que se recabaron informaciones sobre la fundación de estas Haciendas. También se abordaron las técnicas de Investigación Documental, referida a la investigación bibliográfica en libros y tesis relacionados en el tema de las Haciendas y sus sistemas constructivos.

b). Investigación de Campo: En este punto de gran importancia abarca desde la observación, toma fotográfica y elaboración de croquis arquitectónicos in situ de dicha Hacienda, dedicada, como se ha mencionado, a la agricultura, ganado mayor y menor, se analizaron las técnicas y sistemas constructivos que aún prevalecen y que ayudarán, junto con la parte histórica, a tomar las decisiones correctas para una futura restauración y conservación.

Antecedentes de la Hacienda. La ex Hacienda de Montoya, de acuerdo con la investigación histórica, surge a partir del siglo XVII; estaba compuesta de un vasto territorio, que se ubica en los Valles Centrales de la Verde Antequera, al poniente de la Ciudad, en la calle Camino Real (Figura 3); antiguamente esta finca estaba sujeta a la municipalidad del Marquesado, su ubicación es privilegiada por la cercanía con las ruinas prehispánicas de Montealbán.

De acuerdo con fuentes primarias, y a documentos proporcionados por los actuales propietarios, se sabe que esta Hacienda tuvo una vida útil de 300 años, sin tener dato preciso de su construcción, considerando como fundador de la "Hacienda de Montoya, al Señor Don Baltasar Montoya y Maldonado; ya que pide merced de tierra y agua en el año $1719^{\prime \prime}$. Se puede observar en la Figura 4 la ex Hacienda con la ubicación de puestos de control y sus garitas de entrada a la ciudad, ubicando las Haciendas más importantes, en sus cuatro puntos cardinales; estas representaban la seguridad y el sostén económico de la ciudad oaxaqueña.

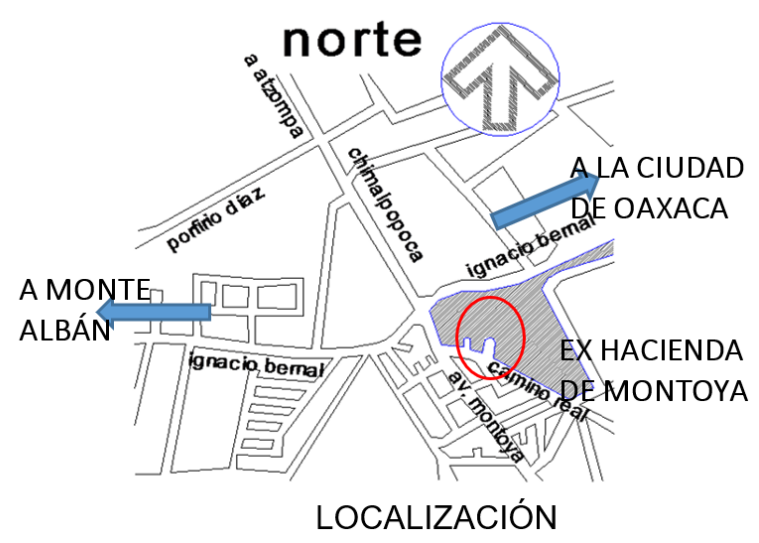

Figura 3. Ubicación actual de la ex Hacienda de Montoya

Fuente: Elaborado por la autora.

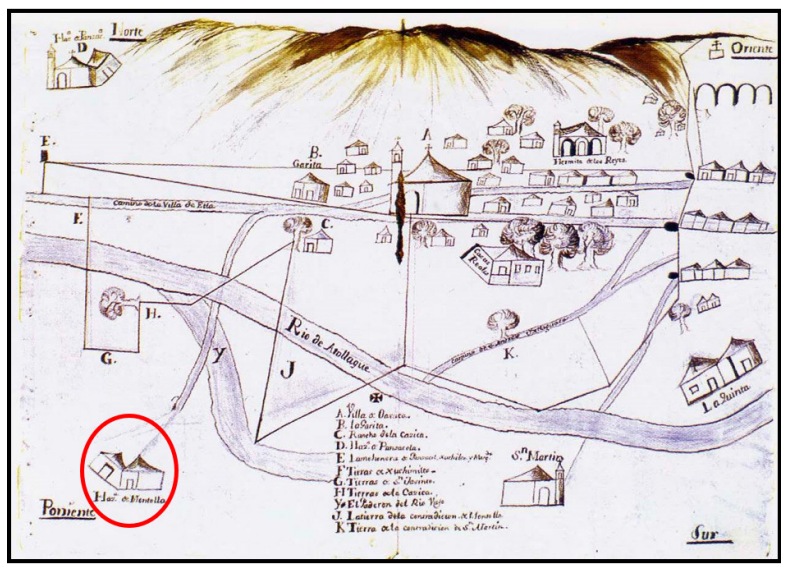

Figura 4. Plano del Marquesado de Oaxaca. Año de 1760. Fuente: Archivo General de la Nación en ciudad de México. Ramo: Mapas, planos e ilustraciones. http://www.agn.gob.mx/guiageneral/Imagenes/ index1.php?CodigoReferencia=MX09017AGNCL01SB01FO178 MAPILUUS3027\&Tipo=H.

\footnotetext{
1. Archivo General de la Nación en Ciudad de México. Composición de tierras. Contenedor 21 Vol.70. Folio 73 verso. Año 1719. Instituciones Coloniales/ Real Audiencia/ Mercedes (072). Archivo de Notarías de Oaxaca. Libro 121, Folio 65, Documento: Poder especial. Año 1719. Balthazar (sic) de Montoya Maldonado Caballero de la Orden de Calatrava, regidor y dueño de hacienda de campo y labor. Da su poder para que en su nombre comparezca ante el juzgado conveniente para que se le haga merced del agua que tiene una charca a la hacienda de campo y labor del otorgante que tiene en términos de la Villa de Oaxaca y del Marquesado del Valle, en la cantidad de 20 pesos que ofrece por el servicio.
} 
Características Espacio-Formal. La ex Hacienda de Montoya presenta la siguiente disposición: (Figura 5).
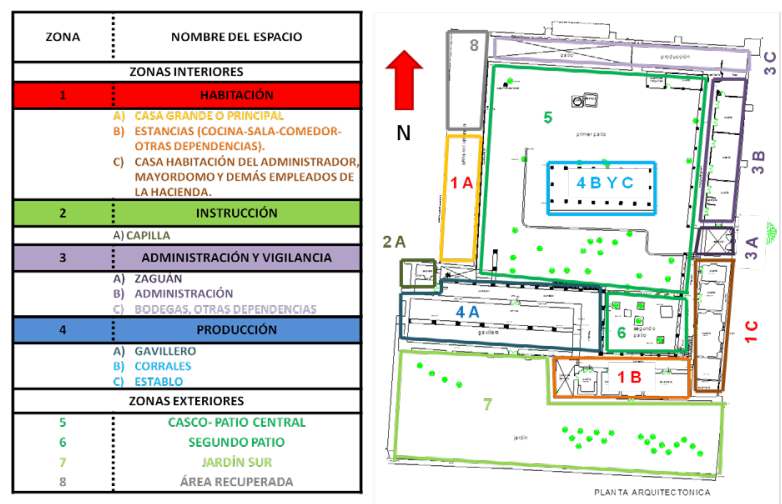

Figura 5. Ubicación de áreas ex Hacienda de Montoya. Fuente: Elaborado por la autora.
Las zonas $1 \mathrm{~B}, 1 \mathrm{C}$ y $4 \mathrm{~A}$ se ubican en el sur-oriente; sus partidos arquitectónicos se encuentran bien unificados, y pertenecían a la unidad de lo que fue el casco de la Hacienda. Las zonas 3 B y 3 C (administración y bodegas) son relativamente nuevas, se modificaron con materiales actuales y se hicieron para albergar una planta productiva de pinturas; solo respetaron los muros colindantes que son de adobe. La zona $1 \mathrm{~A}$ fue destruida, y posiblemente esta zona podría ser la casa grande, por estar ubicada a un lado de la capilla (zona 2 A); quedan vestigios de lo que hubo, una arcada, de la cual quedan dos arcos en pie y un pilar, con algunos accesos y ventanas tapiadas. (Véase Figuras 6 al 10).

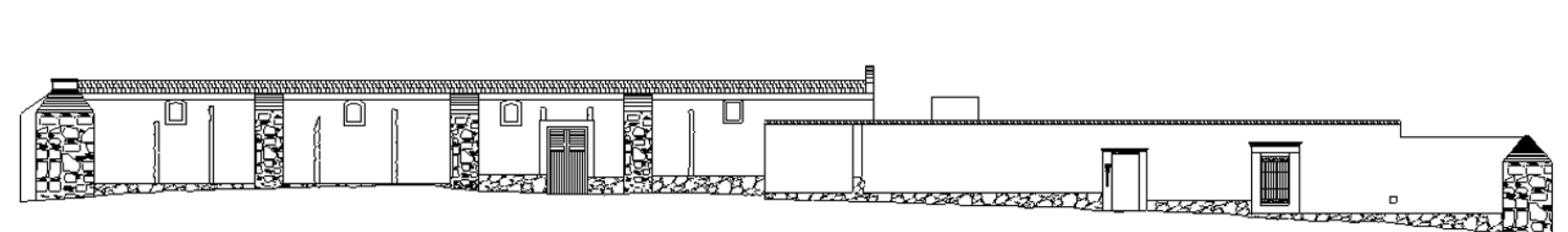

Figura 6. Elevación sur s/e. Ex Hacienda de Montoya. Fuente: Elaborado por la autora.

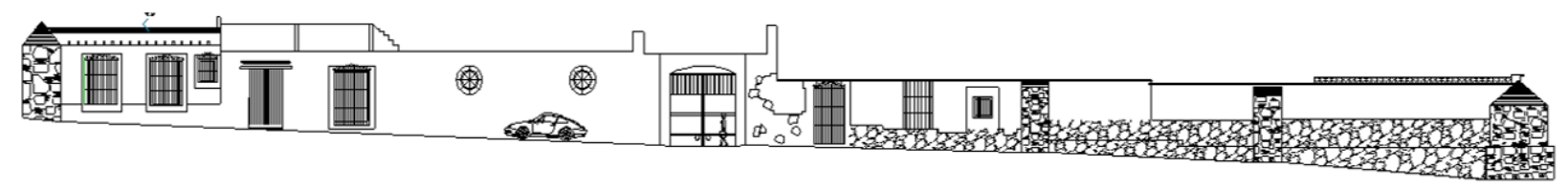

Figura 7. Elevación oriente s/e. Ex Hacienda de Montoya. Fuente: Elaborado por la autora.

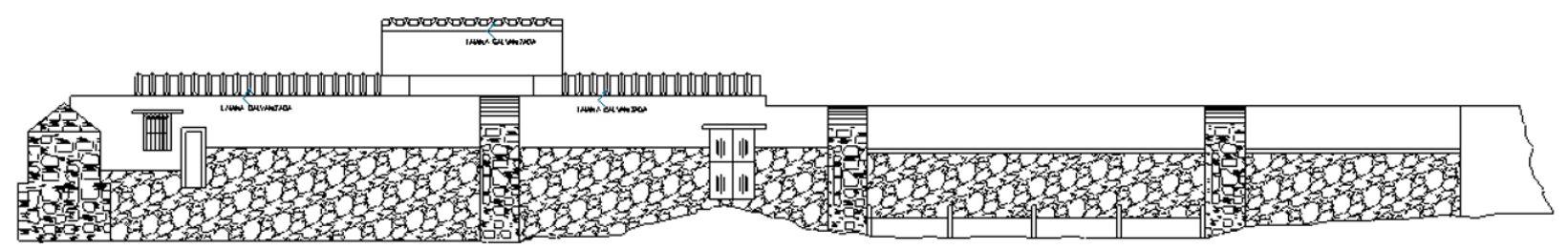

Figura 8. Elevación norte s/e. Ex Hacienda de Montoya. Fuente: Elaborado por la autora.

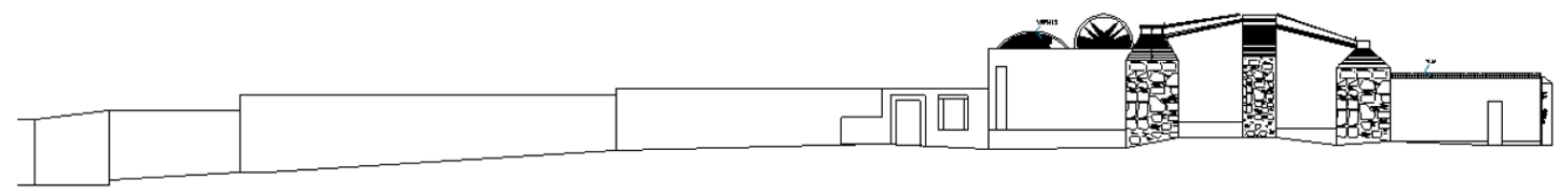

Figura 9. Elevación poniente s/e. Ex Hacienda de Montoya. Fuente: Elaborado por la autora.

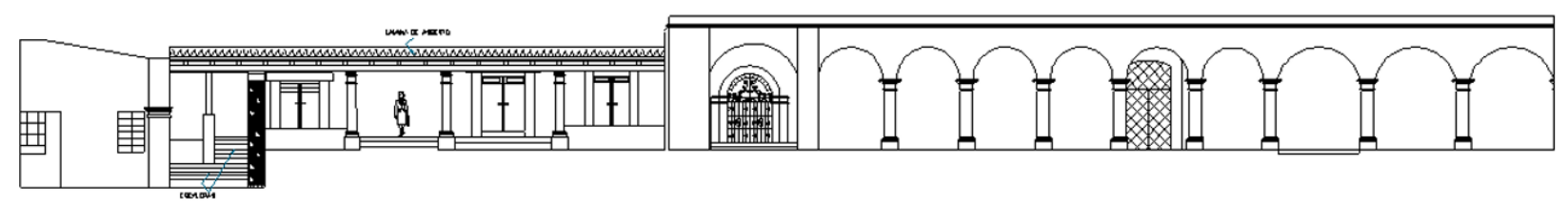

Figura 10. Elevación interior sur s/e. Ex Hacienda de Montoya. Fuente: Elaborado por la autora. 


\section{Materiales y Sistemas Constructivos de la Hacienda}

Cimientos. El subsuelo, en especial en el territorio de Oaxaca, corresponde a una zona sísmica, en donde las bases de cimentación son a base de piedra, formando grandes terraplenes de piedra unidos con un mortero a base de lodo, cal y arena, a la manera prehispánica; este mortero ha dado a las construcciones una extraordinaria elasticidad imposible de igualar con otro tipo de aglutinante, y claramente se pueden observar en la Hacienda,

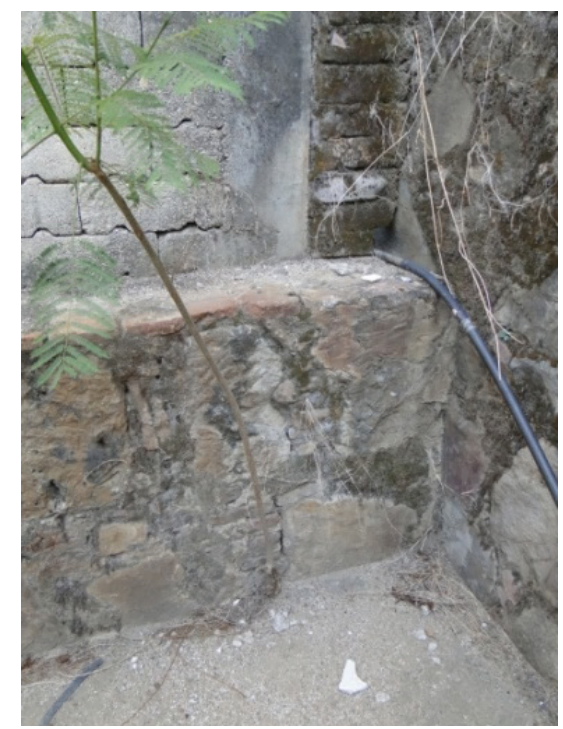

Figura 11. Plataforma de piedra o piedraplen área de patio. Fuente: Archivo fotográfico de la autora 2018. en especial en el área del gavillero y algunas áreas perimetrales.

Durante las excavaciones encontraron cimientos de sección rectangular con un ancho igual del espesor del muro, sobresaliendo del nivel de la tierra, y a partir de ahí se desplantan los muros de adobe evitando estar en contacto con la tierra natural; en otras áreas se observa parte de una plataforma continua. Tal es el caso de las áreas de los corredores, como se muestran en las siguientes Figuras 11, 12 y 13.

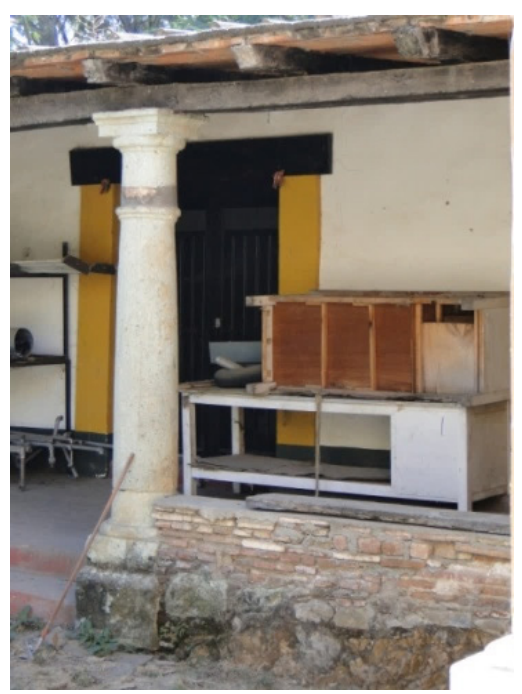

Figura 12. Exteriores del área del gavillero y corredores interior de la ex Hacienda de Montoya.

Fuente: Archivo fotográfico de la autora 2018.

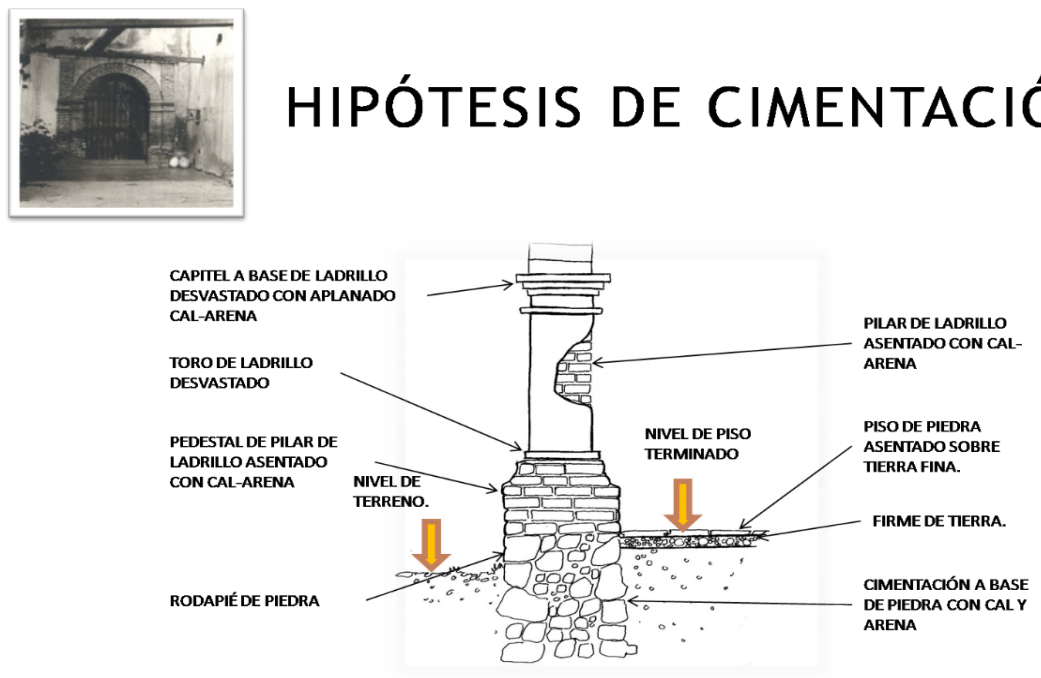

DETALLE 4 DE CIMENTACIÓN EN ÁREA CORREDOR JUNTO AL GAVILLERO

Figura 13. Detalle de cimentación junto al gavillero. Fuente: Elaborado por la autora. 
Pisos. Consistentes en pisos de tierra apisonada, sobre el cual se colocaba la piedra bola o canto rodado, asentados también con mortero cal-arena, en especial, en el área de gavillero, corredores y patios, tal como se muestra en la Figura 14. No se tiene ningún vestigio que indique el tipo de piso que tenían en los interiores las distintas áreas de la Hacienda, pero se puede pensar que se colocaba un entarimado de madera, o baldosas de barro.

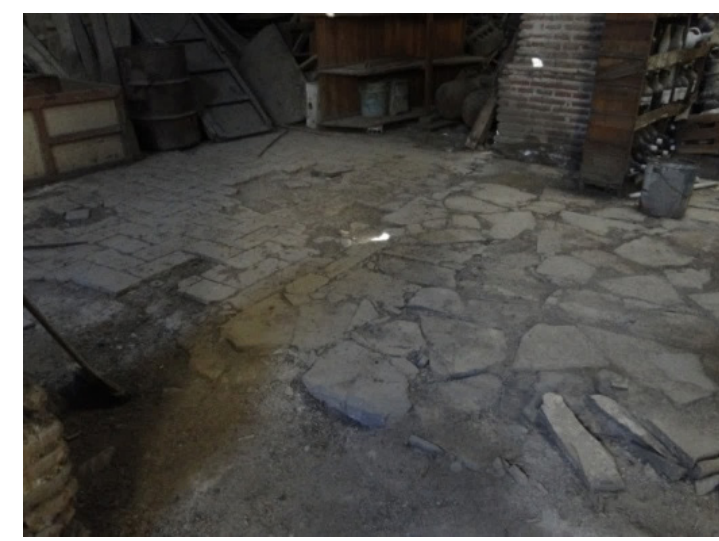

Figura 14. Tipo de piso, de piedra natural y ladrillo asentado sobre tierra, en el interior del área del gavillero. Ex Hacienda de Montoya.

Fuente: Archivo fotográfico de la autora 2018.

Muros. Las medidas de longitud que se utilizaba era la vara, el pie castellano y el palmo o cuarta (cuarta parte de la vara). La vara usada en México se estima igual a $83.8 \mathrm{~cm}$., una vara era igual a tres pies castellanos o cuatro palmos. Por lo tanto, un pie castellano resulta ser de $27.93 \mathrm{~cm}$., y el palmo de 20.93 $\mathrm{cm}$. (aproximadamente 28 y $21 \mathrm{~cm}$., respectivamente); un palmo se dividía en 12 dedos, es decir un dedo igual a $1.74 \mathrm{~cm}$., siendo estas las unidades de los elementos constructivos más utilizados, en el siglo XVI y XVII (Rocha, 2013, pp. 64-79).

En la ex-Hacienda podemos observar muros mixtos formados por piedra, ladrillo, o mixto piedra y adobe; presentan aplanados con mortero de cal y arena, con espesores que varían de 1.00 metro hasta 80 centímetros de espesor. Los muros de adobe son de un espesor variable que llega a ser de hasta de 1.00 metro; su colocación se realizó en forma cuatrapeada entre hilada e hilada, con la finalidad de dar mayor amarre al elemento constructivo. En el siguiente croquis podemos observar estos detalles (Figura 15). En cuanto a sus aplanados, se utilizó el lodo o mezclas de cal y arena, frecuentemente pintados con cal, cubriendo muros de adobe, tabique o cantera.

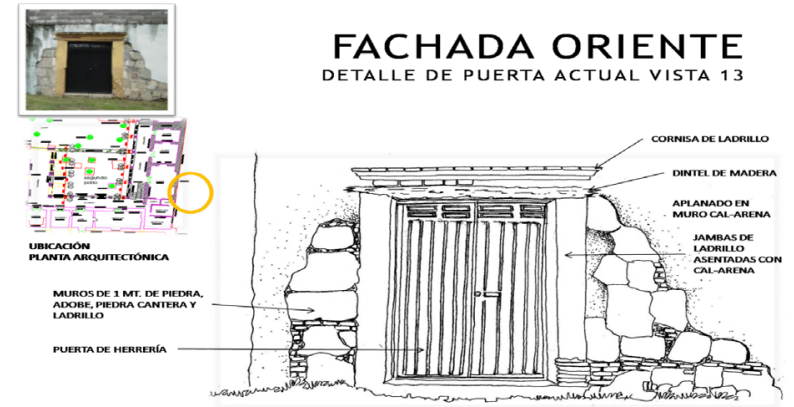

Figura 15. Detalle de puerta actual en fachada oriente ex Hacienda de Montoya.

Fuente: Elaborado por la autora.

Arcos. Este elemento constructivo era uno de los más conocidos; fueron utilizados en forma muy rústica con piedra. Este elemento fue una novedad en la Nueva España. En la ex-Hacienda se construyeron en ladrillo, con ausencia de claves y un trazo sin plantillas. Esto se puede observar en algunos de forma desigual y carentes de experiencia; obsérvese las siguientes Figuras 16 y 17.

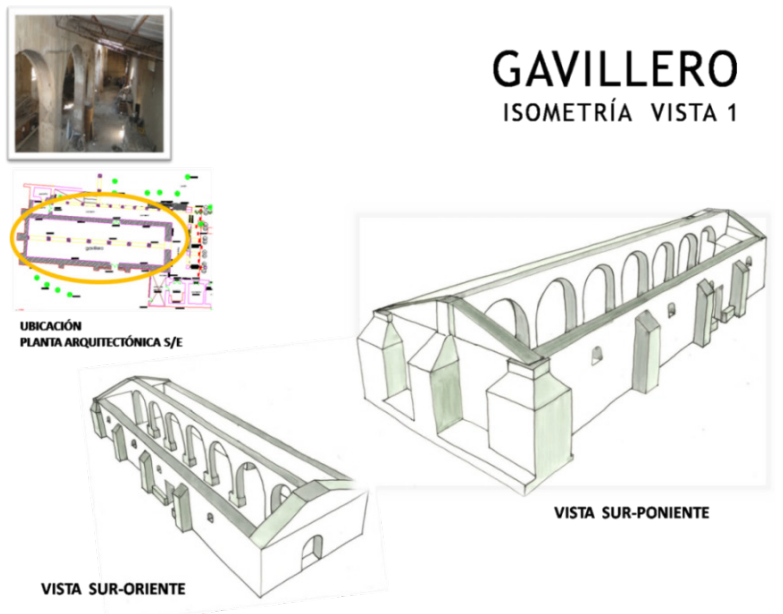

Figura 16. Área de gavillero.

Fuente: Elaborado por la autora.

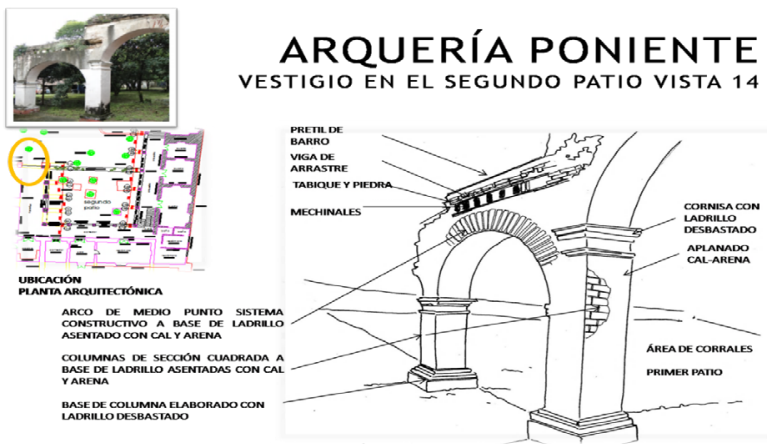

Figura 17. Detalle de arquería poniente del primer patio. Fuente: Elaborado por la autora. 
Detalles Interiores del Gavillero. Las dimensiones convencionales de los tabiques de barro consideradas eran de $0.7 \times 0.14 \times 0.28$ centímetros, en realidad son $1 / 4$ pie $X 1 / 2$ pie $X 1$ pie castellanos. También encontramos ladrillos de $0.3 \times 0.14 \times 0.28$ centímetros, particularmente en el interior de los arcos del gavillero; estas medidas indican que posiblemente fueron edificados a principios del siglo XVIII.

El barro (tierra más agua) fue la base de materiales manufacturados, tal es el caso del adobe, del ladrillo y la teja, en el que tenemos evidencia en el Testamento de Don Baltasar Montoya cuando compra estas tierras menciona que: "incluyéndose en dicha venta dos labores con cuatro caballerías de tierras y un pedazo que compró a los naturales del pueblo de San Martín en ciento diez pesos. Las casas principales de la Estancia, las de dichas dos labores, las que en ellas he edificado y reedificado, un corral de piedra, dos hornos de sacar cal, dos de ladrillo y teja, las aguas, pastos y abrevaderos." Esto nos indica que desde 1713 estas edificaciones se hicieron de ladrillo, teja y cal.

"Los ladrillos (denominados en algunos lugares como tabiques), por el contrario, necesitaban de mayor conocimiento técnico al tener que utilizar la arcilla, lo más limpia posible de impurezas, batirla, moldearla y cocerla en un horno con los conocimientos anexos que ello suponía. En el mismo sentido sucede con la teja que era una forma importada de España y que se generalizó en las zonas lluviosas en sustitución del tejamanil que era menos duraderas en el tiempo." (López, 2007, p. 202).

Cubiertas. Las cubiertas fueron muy variadas $y$, de acuerdo con algunos documentos y fotografías, nos ejemplifica el sistema que se tenía; hoy en día ninguno de ellos prevaleció debido al tipo de material que se utilizaron, tal es el caso de las vigas de madera, carrizo, morillos, terrado y tejamanil, y el barro. (Figura 18).

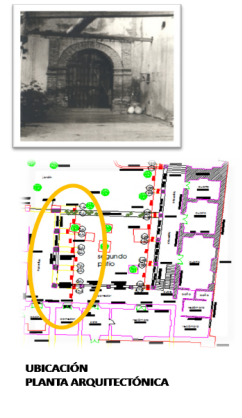

\section{HIPÓTESIS DE SECCIÓN DE TECHUMBRE}

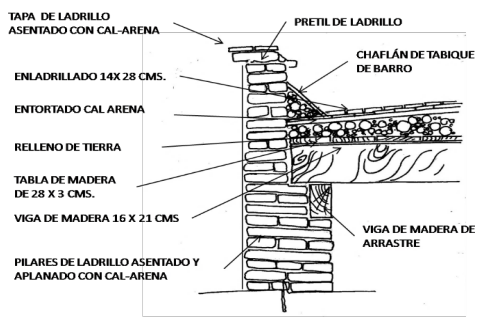

DETALLE 2 de TECHUMBRE EN ÁrEA CORREDOR JUNTO AL GAVILLERO

Figura 18. Detalle de techumbre en área corredor junto al gavillero.

Fuente: Elaborado por la autora.

Se hacen algunas hipótesis acerca del tipo de cubiertas que pudieron haber tenido en aquella época y, de acuerdo con los sistemas constructivos que aún prevalecen en el caso de las Haciendas Oaxaqueñas, mencionando las siguientes:

1.- Techumbres de viguería horizontal de madera, con terrado y enladrillado o teja. (Soluciones ampliamente usadas con ritmos conocidos de "entre viga y viga, viga" y "viga parada, viga acostada".

2.- Techumbres de pendientes con armadura de madera para claros grandes, con terrado y teja, en donde podemos observar en la siguiente Figura 18 la hipótesis de la techumbre en corredores, de acuerdo con algunos vestigios existentes.

3.- Cubiertas con bóveda de cañón construida en mampostería, que posiblemente haya tenido la capilla, sin tener la seguridad de ello.

4.- Cubiertas de viguería horizontal de morillos con tejamanil y también de paja, que fue un sistema de cubierta muy tradicional en las Haciendas, sobre todo en las áreas de caballerías y establos.

Dinteles. El dintel es otro elemento constructivo antiguo, que ha prevalecido en la actualidad; los encontramos comúnmente como refuerzo superior en puertas y ventanas, aunque sus vanos están hechos a base de ladrillo o piedra cantera, muy característico de esa época, en la ex Hacienda aún se conservan algunos dinteles, según como se observa en la Figura 19.

2. Biblioteca Fundación Bustamante Vasconcelos en Ciudad de Oaxaca. Testimonio del Testamento de Don Baltazar Montoya y Maldonado Caballero de la Orden de Calatrava, en el año de 1733, inserto en el Testamento de Doña Ángela Montoya Varela y Olivera año de 1765. N 4 718-159. Año 1733- 1765. Folio 184 verso. 


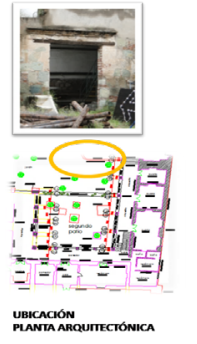

\section{DETALLE DE PUERTA NORTE \\ PRIMER PATIO ACTUAL VISTA 15}

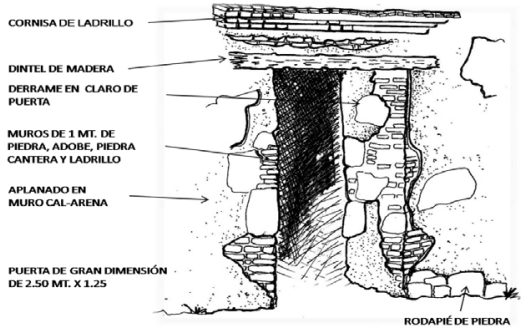

Figura 19. Detalle de puerta actual en fachada interior norte. Fuente: Elaborado por la autora.

Contrafuertes. Estos elementos constructivos que sirven para contener los efectos de las cargas transmitidas en las techumbres a los muros, o que sirven para apuntalar los muros, los encontramos en las esquinas de los muros tanto del gavillero como los perimetrales de la ex Hacienda de Montoya.

Los materiales que utilizados en la edificación fueron a base de piedra y ladrillo en forma combinada, y posiblemente deben haber estado aplanados con mortero de cal y arena, se tiene una muestra fotográfica del siglo pasado año cincuenta, donde aún existían los remates de estos contrafuertes, hoy desaparecidos, claramente lo podemos observar en las Figuras 20, 21 y 22.

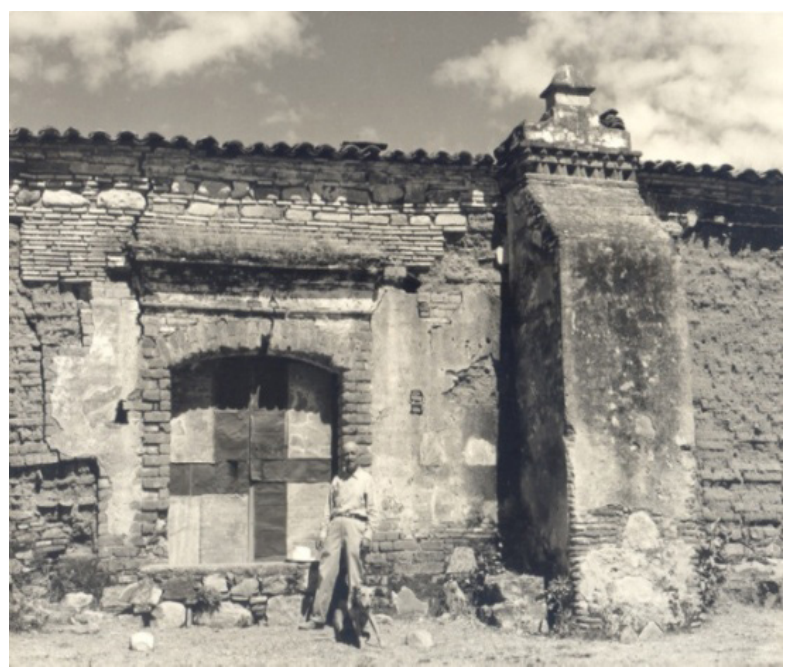

Figura 20. Contrafuerte en área de gavillero año de 1950. Fuente: Archivo Fundación Bustamante Vasconcelos, Oaxaca.

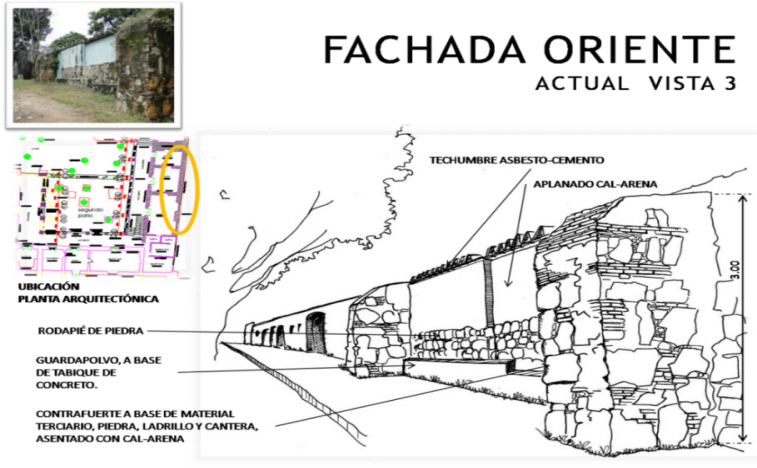

Figura 21. Detalle de contrafuertes en fachada oriente. Fuente: Elaborado por la autora.

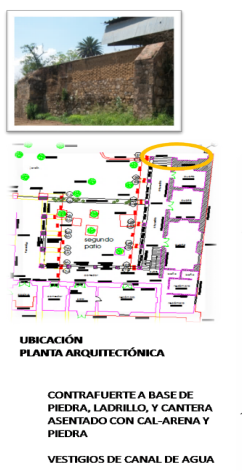

FACHADA NORTE ACTUAL VISTA 4

Figura 22. Detalle de contrafuertes en fachada norte. Fuente: Elaborado por la autora.

Herrería. El Hierro fundido no se utilizó durante la época colonial. Es una innovación europea, producto de la Revolución Industrial, aplicada a la Arquitectura del viejo continente a mediados del siglo XIX, generalizándose el uso de esta tecnología en México durante el Porfiriato (Terán B, 1998, p.87). Encontramos pocas muestras de herrería en algunas ventanas, sobre todo en fachada norte (muros actuales área de taller) perteneciente al siglo pasado.

Pruebas de Campo. Hay que destacar en este punto la importancia de llevar a cabo las pruebas de campo; de alguna manera, el conocer y sentir los materiales fueron de vital importancia para tomar decisiones y hacer las propuestas idóneas para restaurar el edificio de estudio. Los materiales naturales son más durables si les damos periódicamente un mantenimiento preventivo; estas pruebas de campo que son sencillas y no costosas, se llevaron a cabo en el lugar, y ayudaron a determinar las proporciones aproximadas de los componentes de la tierra, también su plasticidad y posible resistencia. 
Identificación Física del Adobe en la ex Hacienda de Montoya. Para estudiar y entender el deterioro de un material hay que empezar por sus orígenes, ya sea estudiando los procesos de deterioro a los que se ha sometido el material o los materiales de forma físico-mecánica, química y/o biológica. Una manera sencilla de estudiar el deterioro es partiendo de los efectos que el material presenta, que es todo aquello que nosotros podemos ver, con la finalidad de entender las causas que les dieron origen, así como los mecanismos que actuaron en la modificación de las propiedades de cada material.

Primeramente, se llevó a cabo un análisis físico del adobe existente del lugar: para ellos se hicieron dos pruebas, uno de un adobe viejo, cuya finalidad fue sacar la proporción de sus componentes, que ayudaron a diseñar una propuesta para la fabricación de adobes nuevos por faltantes, y la otra, revisar si el tipo de tierra del lugar está apta para llevar a cabo dicha fabricación (Tabla 1).

Tabla 1. Propiedades Físicas del Adobe.

$\begin{array}{cc}\text { Humedad } & \text { Retracción longitudinal } \\ \text { Olor } & \text { Retracción volumétrica } \\ \text { Color } & \text { Plasticidad } \\ \text { Textura } & \text { Maleabilidad } \\ \text { Adherencia } & \text { Posible Resistencia }\end{array}$

Elaboración propia

Estudio del Suelo en el Lugar. Para estudiar el suelo y saber sus características se debe conocer la parte mineral. Esto no tiene nada que ver con el análisis de tierra que sirve para saber la cantidad de elementos nutritivos, químicos y orgánicos, que están en el suelo y que "tan solo" sirven para saber la política de abonado que deberemos seguir y la riqueza nutricional del suelo. El procedimiento realizado para el estudio, consistió en el uso de una malla dónde se cribó la tierra para separar las partes sólidas que tuvieran más de $2 \mathrm{~mm}$ de grosor, piedras, gravas y materia orgánica. Después, con la tierra fina restante se llevó a cabo un análisis granulométrico y, de esta manera, se observó su textura y estructura (Figuras 23 y 24).

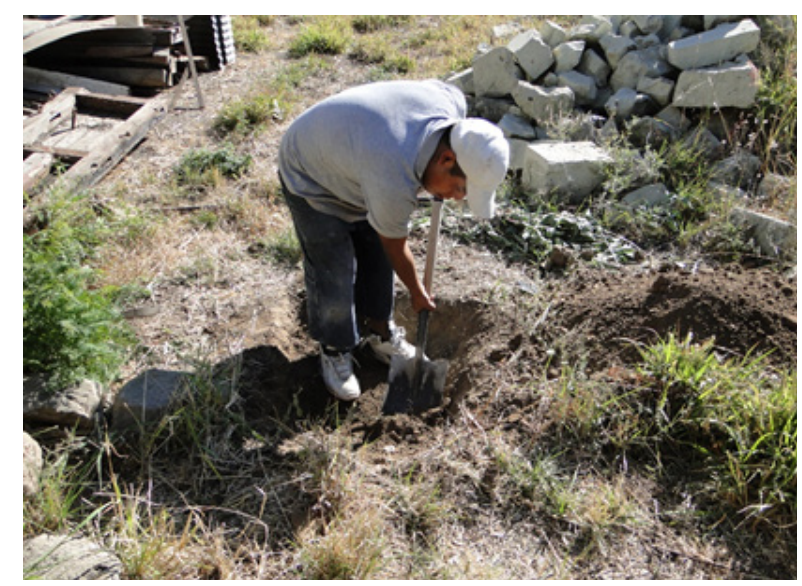

Figura 23. Extracción de tierra en la ex Hacienda de Montoya. Fuente. Archivo fotográfico propiedad de la autora.

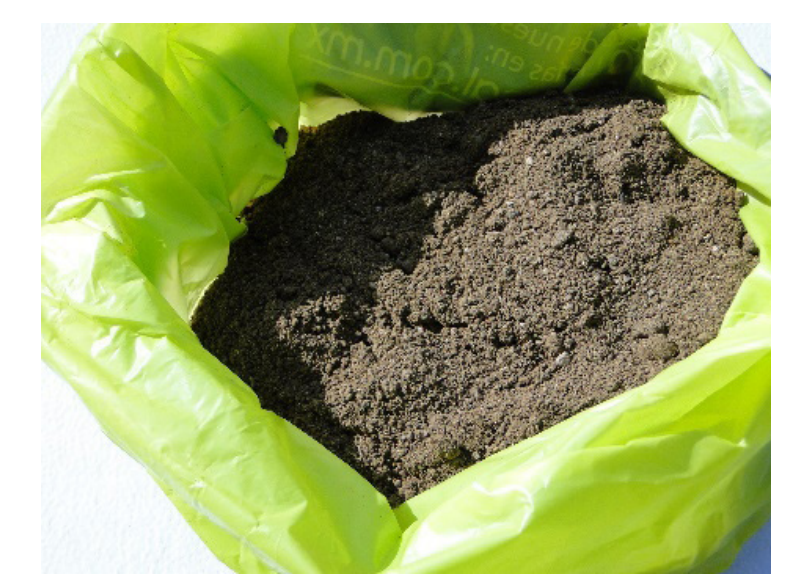

Figura 24. Muestra de tierra de la ex Hacienda de Montoya. Fuente. Archivo fotográfico propiedad de la autora.

Textura. La textura es su estructura y disposición, se refiere al tamaño de las partículas que tiene la tierra y su proporción; en él se podrá observar si la textura es arenosa, arcillosa o limosa, en diferentes proporciones.

Arena. Son las partículas de origen principalmente silícico y que tienen una granulometría de entre 0.02 y $2 \mathrm{~mm}$.

Limo. Son partículas de cualquier origen químico y que su granulometría oscila entre 0.02 y $0.002 \mathrm{~mm}$. Arcilla. Hay de diferentes tipos, compuesta de silicatos y con un tono rojizo, debido a los óxidos de hierro, y que posee una granulometría inferior a $0.002 \mathrm{~mm}$. Según los porcentajes de diferentes elementos, se podrá determinar si una tierra es más compacta o más suelta, en pocas palabras, si es apta para la fabricación de nuevas piezas de adobe. 
A continuación, se mostrará la prueba que se realizó a una pieza de adobe que se desprendió del área del gavillero en la ex Hacienda de Montoya, con la finalidad de sacar la proporción y sus características, de acuerdo con lo mencionado con anterioridad.

Descripción. La muestra correspondió a una tierra que había sido parte de un adobe bastante antiguo, aproximadamente más de 50 años. Las medidas, características y resultados obtenidos son los siguientes:

\section{RESULTADOS}

Con lo mencionado, se procedió a realizar las pruebas que a continuación se muestran en la Tabla siguiente:

Tabla 2. Análisis y Pruebas de Tierra del Lugar y Adobe

\begin{tabular}{|c|c|c|}
\hline Característica & Descripción escrita & Fotografía \\
\hline Humedad & 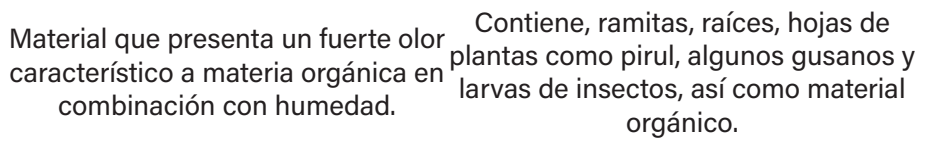 & \\
\hline Olor & 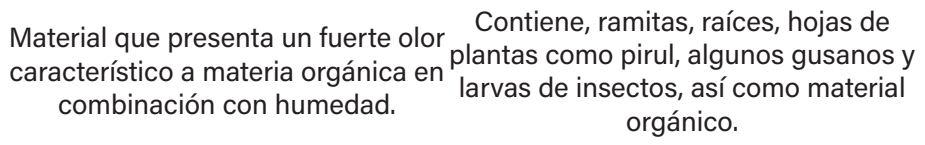 & \\
\hline Textura & $\begin{array}{cc}\text { Al tacto sobre las yemas lo que se } \\
\text { La muestra contiene una gran } & \text { percibe son dos texturas una gruesa } \\
\text { cantidad de arenas, combinada con } & \text { que corresponde por su tamaño del } \\
\text { pequeños guijarros, limo y arcillas } & \text { grano a una arena, y otra de textura } \\
\text { en una pequeña proporción. } & \text { fina tasqueada, que corresponde } \\
\text { al limo por el color café oscuro que } \\
\text { presenta la muestra. }\end{array}$ & \\
\hline Adherencia & $\begin{array}{cc}\begin{array}{c}\text { La muestra presenta una } \\
\text { adherencia debido a la presencia en } \\
\text { primer lugar de una alta humedad } \\
\text { y en segunda por un contenido } \\
\text { elevado arcilla. }\end{array} & \begin{array}{c}\text { Al estar manipulando el material, } \\
\text { de arena, con el limo, aunado a }\end{array} \\
\begin{array}{c}\text { la concentración considerable de } \\
\text { humedad dentro del material, la }\end{array} \\
\text { muestra presentó una alta adherencia. }\end{array}$ & \\
\hline $\begin{array}{l}\text { Retracción } \\
\text { Longitudinal }\end{array}$ & $\begin{array}{l}\text { Esta prueba consistió en formar } \\
\text { una tira circular de } 1 \mathrm{~cm} \text { de diámetro } \\
\text { por } 15 \mathrm{~cm} \text { de longitud de material } \\
\text { adicionando una pequeña cantidad } \\
\text { de agua, con el objeto de buscar } \\
\text { más maleabilidad al desarrollar este } \\
\text { ejercicio. Por lo que se dejó secar } \\
\text { la pieza y se observó que existió } \\
\text { una reducción en su longitud de } \\
0.30 \mathrm{~cm} \text {, dando una longitud final de } \\
14.70 \mathrm{~cm} \text {. }\end{array}$ & - \\
\hline
\end{tabular}


Para esta prueba se formó una pequeña esfera de $4-5 \mathrm{~cm}$ de diámetro, adicionando agua para lograr una consistencia

Plasticidad manejable de la tierra de adobe. Posteriormente se cortó la esfera por su parte media, mediante el uso de una lámina, en un solo movimiento.
La parte grafica del experimento consistió en observar detenidamente el corte de una sección del material, detectando una pequeña superficie brillosa en un extremo del corte, esto no indica la presencia en una proporción considerable de limo en la muestra de tierra de adobe, lo cual explica el porqué de la gran plasticidad de esta tierra, en el momento de manipularla.
Para esta prueba se utilizó un frasco de vidrio de unos $5 \mathrm{~cm}$ de diámetro por unos $10 \mathrm{~cm}$ de altura el cual se llenó $3 / 4$ de su capacidad con la muestra de tierra de adobe, adicionando agua limpia hasta el "ras" del frasco, procediendo a

Asentamientos agitarlo hasta que la tierra quedara Sólidos completamente disuelta en el agua y no presentara grumos de material; y que finalmente se dejó reposar hasta que el agua en la parte superior del frasco no presentara una apariencia turbia, que para nuestro caso fue alrededor de 1 hora aproximadamente.

El objetivo de este experimento es saber tentativamente el porcentaje de los sólidos que componen la muestra de tierra, es decir saber aproximadamente los porcentajes de arenas, limos y arcillas.

Esto se detectó, además con base en la coloración que presento cada una de las fases que se produjeron dentro del frasco, que en este caso fueron:

1. Arenas: color gris oscuro aproximadamente un $60 \%$ del volumen de la muestra de tierra. 2. Limos: color café-rojizo oscuro, el cuál fue de $20 \%$ del volumen total de la muestra de tierra.

3. Arcillas: en este caso el porcentaje de arcillas fue menor del $20 \%$, ya que no presento la característica coloración blanco-crema, que nos indica la presencia de este material, por lo que el restante $4.5 \%$ faltante, correspondió a espacios vacíos y otros materiales que componen la muestra, y que no entran dentro del análisis del material puesto que para su estudio se hace necesario el empleo de equipo y técnicas más específicas.

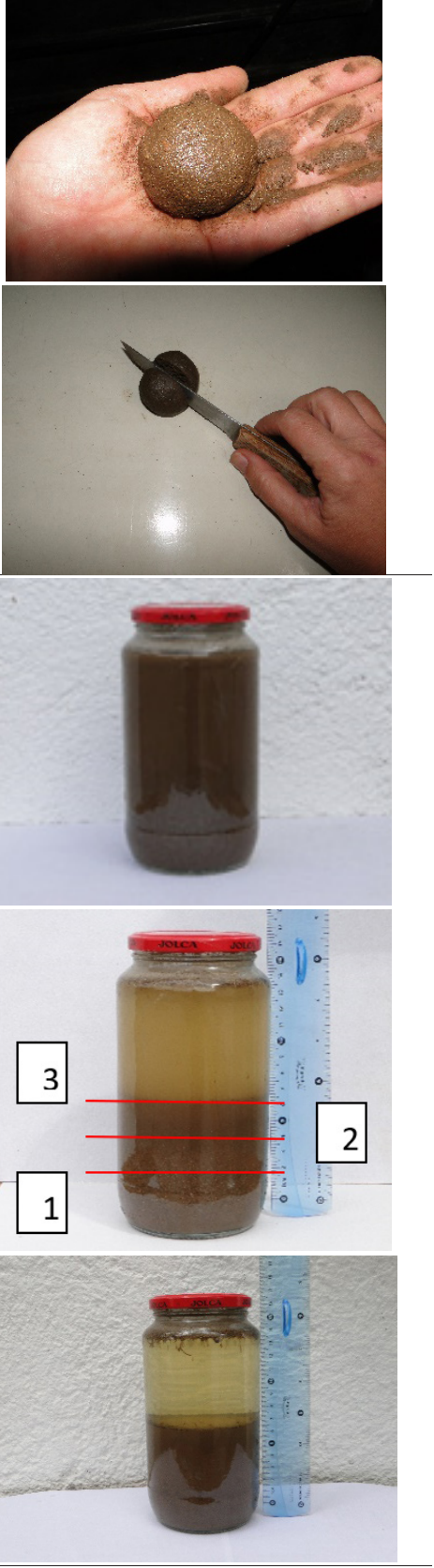

Sobre la superficie del material seco, se observaron una serie de grietas paralelas, lo cual nos vuelve a hacer mención en la desproporción los sólidos que constituyen la muestra; es

Para esta muestra se colocó sobre un mosaico de $30 \mathrm{~cm}$ por $30 \mathrm{~cm}$, una solución de tierra de la muestra

Retracción Superficial con una concentración elevada de humedad.

Dejando que secara la muestra por unas horas y se observó lo siguiente. decir, entre arena dentro de la muestra con una cantidad menor, y el limo con una proporción mucho mayor, y la falta de arcilla dentro de la muestra que fungiera como cementante; lo cual quedó evidenciad en el tamaño y separación de la grieta así como el patrón de agrietamiento del material; que en nuestro caso presento una serie de grietas paralelas y con una separación más perceptible que en el resto de las muestras. 


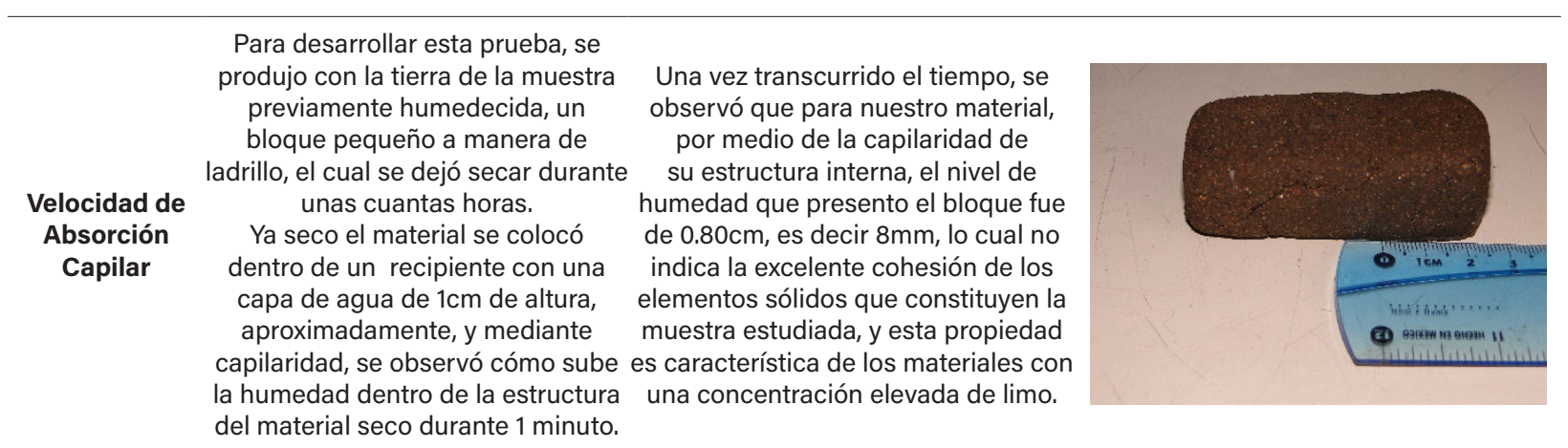

Prueba de Inmersión

Prueba de la
Galleta
(Para
determinar la
resistencia a la
compresión)

La prueba de la "galleta" se utiliza para poder determinar tentativamente una resistencia mecánica a la compresión del material, con el objeto de saber si es o no proclive a ser utilizada en la conformación de sillares para construcción.

El bloque utilizado en la prueba de velocidad de absorción capilar, se colocó dentro de un recipiente de plástico, vaciando una cantidad de agua por un costado de la muestra hasta que cubriera por completo el bloque de la muestra. Tomando el tiempo exacto desde que se vacía el agua en el recipiente hasta que la muestra queda completamente destruida. manera de "galleta" de $5 \mathrm{~cm} \times 2 \mathrm{~cm}$
El resultado observado es que la muestra queda completamente amorfa y solo se distingue un montón de material en el fondo del recipiente, en nuestro caso la muestra tardó en 15 minutos en perder su escudaría demostrando cierta resistencia ofrecida al paso de la humedad en la estructura interna del material; por lo que queda evidencia a cierta acción del limo que evita que se disgregue la muestra, en presencia de una saturación de agua, lo cual es característica particular de nuestra muestra.

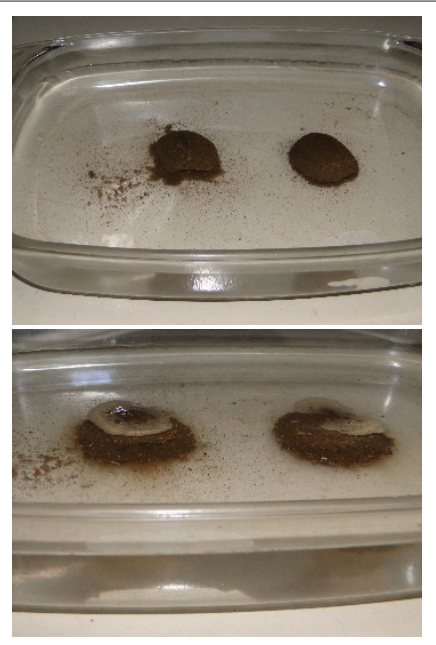

Ya seca la "galleta", el ejercicio consistió en tomarla con los dedos índice y medio, procurando ejercer una presión mediante el pulgar, hasta romper el material, que para nuestro caso no fue posible hacerlo ni siquiera con ambas manos, lo cual pone de manifiesto de nueva cuenta el contenido elevado de limo como material constitutivo de la tierra de nuestra muestra.

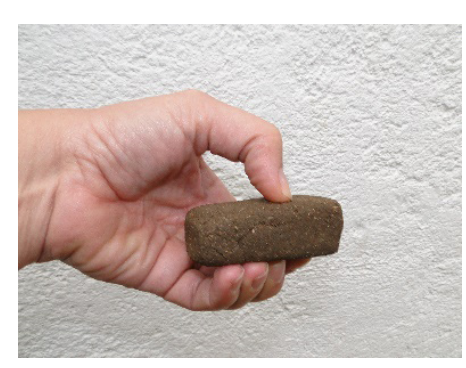

Elaboración propia

$X 1 \mathrm{~cm}$ de espesor, dejándose secar por unas cuantas horas.

\section{Conclusiones de las Pruebas}

Con base en los experimentos anteriores, se logró determinar que la tierra que formó parte del primer adobe analizado, correspondió a un tipo particularmente rico en limo, es decir, proveniente de un suelo "LIMOSO", y que la proporción que presentan sus materiales sólidos constituyentes es buena, tiene una resistencia mecánica a la compresión y a la humedad buenos, siendo un material excelente, y que podría ser la base para sugerir dicha proporción para elaborar piezas de adobe semejantes a los existentes.
Hay dos problemas serios en el adobe a considerar:

1. La humedad, disminuye la resistencia a la tensión y a la compresión del adobe.

2. El agua es otro factor de deterioro que, de alguna manera a pesar del tiempo, la falta de un buen mantenimiento y malas intervenciones, han propiciado que algunos muros se vengan abajo.

El poder llevar a cabo estas pruebas sin utilizar un laboratorio, nos facilitan el detectar las propiedades fisicoquímicas que nos permiten conocer aspectos específicos de los materiales empleados en la fabricación de la Arquitectura de tierra y muy en especial en los adobes. 
Este tipo de pruebas ayudan a la toma de decisiones, para que nuestras propuestas de intervención sean acertadas y exitosas, recurriendo a los mismos materiales y sistemas constructivos en lo que al adobe respecta.

Se llevó a cabo una segunda prueba que se analizó en la tierra del mismo lugar donde se ubica la ex Hacienda de Montoya, y está compuesta de la siguiente manera:

Arcilla $15 \%$

Limo $20 \%$

Arena $65 \%$

Aunque lo ideal sería tener un balance entre los tres componentes, el material que se ensayó en las distintas pruebas nos arroja la siguiente conclusión: el material que se encuentra actualmente en el terreno de la ex Hacienda de Montoya es apto para hacer adobes, con una capacidad de carga buena, y que, en un momento determinado, debido a que la cantidad de arena y arcilla son desproporcionados y bajo el porcentaje de limo, el material se puede mejorar o estabilizar por medio de los distintos métodos de concreción, entramado, acción química e impermeabilización de este material.

Nótese la diferencia de la primera prueba (tapa roja) y la segunda (tapa blanca). Se observan distintas capas derivadas de la composición de la tierra; como se ha mencionado la primera prueba correspondió a un adobe viejo y la segunda a la tierra del lugar (Figuras: 25, 26 y 27).

La tierra del suelo está formada por muchos minerales y, se agrupan bajo tres bloques en función de su tamaño: la arena, el limo y la arcilla. Las dos primeras conforman el esqueleto del sistema y la tercera sirve como aglutinante.
Cuando una mezcla contiene demasiada arena se vuelve hipersensible al agua, de modo que, una vez seca, cualquier variación ambiental de humedad modifica su forma, dimensiones y resistencia. De acuerdo con estudios sobre el adobe Luis Fernando Guerrero Baca (2002), nos sugiere hacer estas mezclas analizando las proporciones de composición de la tierra de cada sitio y determinando si es necesario modificar su dosificación, agregándole arena o arcilla extra, de tal modo que, dependiendo del sistema constructivo que se vaya a utilizar, se logren composiciones cercanas a las siguientes:

- Para adobes y bajareque: $40 \%$ de arena, $40 \%$ de limo y $20 \%$ de arcilla

- Para adobes comprimidos: $65 \%$ de arena, $20 \%$ de limo y $15 \%$ de arcilla.

- Para tapial: $90 \%$ de arena, $5 \%$ de limo y $5 \%$ de arcilla.

Calas en el Lugar. Para descubrir los vestigios ornamentales de una o de diversas épocas en alguna fábrica, puede recurrirse a varios procedimientos, que van desde los más simples hasta los más complejos. De acuerdo con la moderna tecnología, pueden usarse métodos radiográficos, de rebote de sonido, de ultrasonido y muchos otros que se utilizan cuando se está trabajando en escenarios donde se supone pueden existir ocultos elementos arquitectónicos, escultóricos o pictóricos, o de alguna otra manifestación artística de gran valor.

En la ex Hacienda de Montoya se llevaron a cabo calas de piso con la idea de descubrir los basamentos de los pilares que conformaron la arquería del primer patio, y para conocer y asegurar la existencia de ellos. Se llevaron a cabo tres calas de 0.50 centímetros $X 0.50$ centímetros, con diferentes profundidades, esto debido al desnivel del terreno,
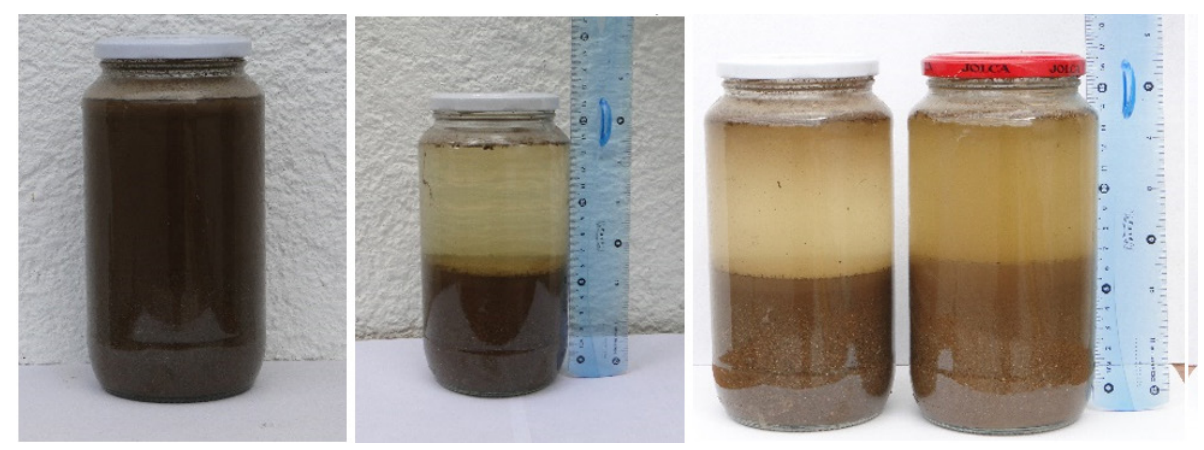

Figuras 25, 26 y 27. Muestras de frascos de tierra de la ex Hacienda de Montoya. Fuente. Archivo fotográfico propiedad de la autora. 
con el siguiente personal y herramienta: un peón, pala, pico y barreta, haciéndolo con el cuidado que esta actividad amerita. Estos restos se ubican exactamente frente a los pilares correspondientes al área del gavillero (Figuras 28, 29 y 30).

El trabajo realizado permite reforzar la tesis planteada en la Carta Internacional de Venecia que señala en su Artículo IX que: "La restauración de un monumento
(...) es una operación que debe guardar un carácter excepcional. Tiene como finalidad asegurar su conservación y revelar o restituir su valor y cualidades estéticas o históricas. Se fundamenta en el conocimiento profundo del monumento (...) así como de la cultura y técnicas que le son relevantes. La restauración se funda en el respeto hacia la substancia original o antigua del monumento (...) y sobre los documentos auténticos que le conciernen" (Carta Venencia, 1978, p. 3).
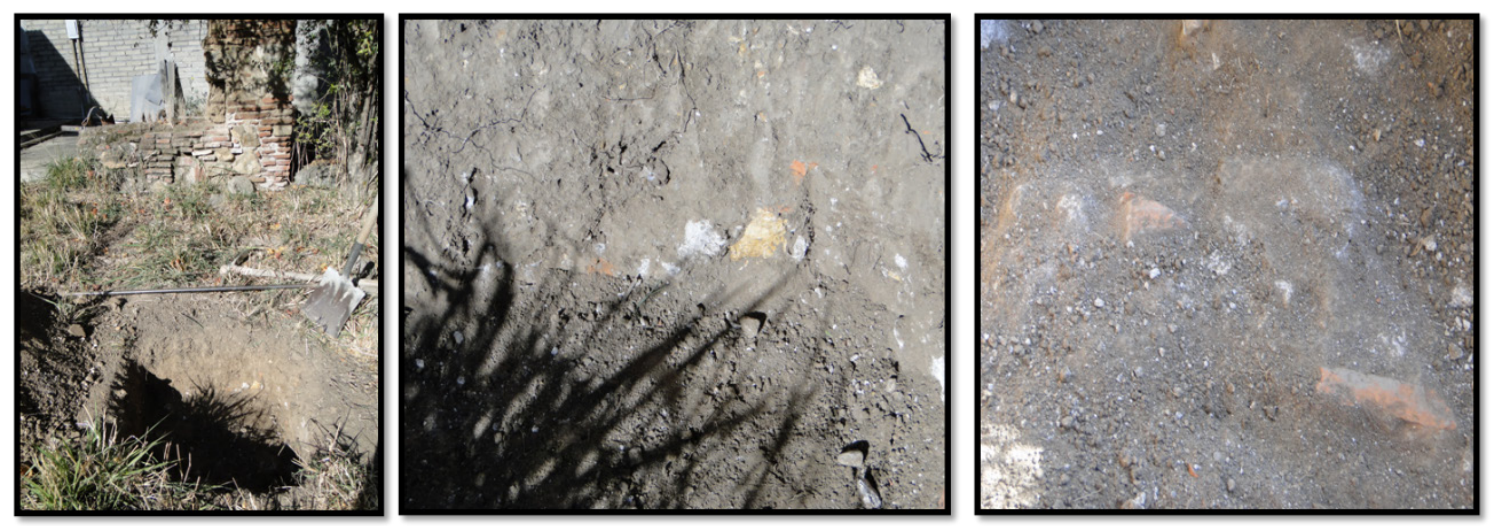

Figuras 28, 29 y 30. Se encontraron restos de los basamentos de los pilares, restos de ladrillo, cal y arena, en las fotografías se aprecia claramente que estas bases existieron.

Fuente. Archivo fotográfico propiedad de la autora.

Por lo que podemos establecer, la propia Arquitectura debe ser considerada como un documento histórico a interpretar, que fue lo que se realizó en la ex

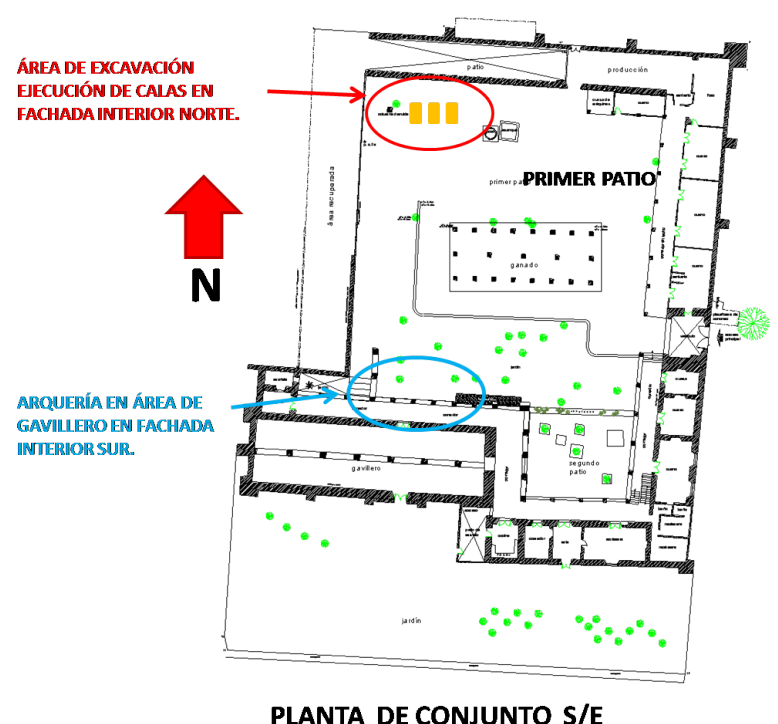

Figura 31. Planta de conjunto ubicación de excavaciones de calas en fachada interior norte del primer patio de la ex Hacienda de Montoya.

Fuente. Archivo fotográfico propiedad de la autora.
Hacienda de Montoya al llevar a cabo las calas, $y$ en caso de reemplazar las partes inexistentes deberán integrarse armoniosamente en el conjunto, distinguiéndose claramente con el resto de las originales, con la finalidad de que la restauración no falsifique el edificio (Figuras 31 y 32).

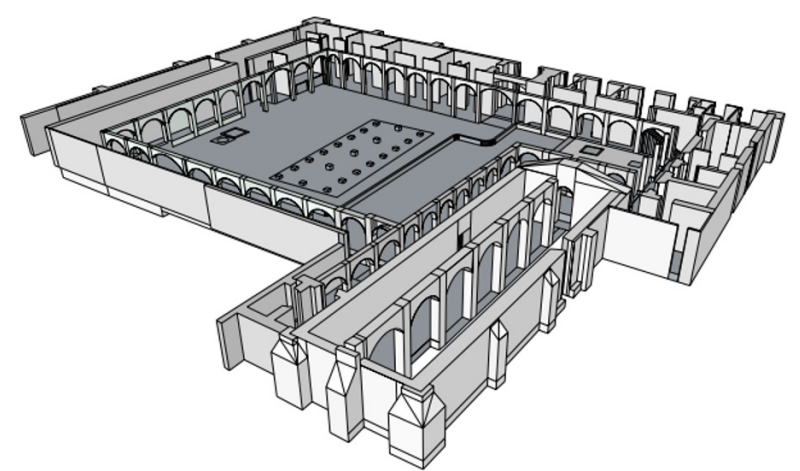

Figura 32. Isométrico de la ex Hacienda de Montoya. Hipótesis de arquerías del primer patio.

Fuente. Archivo fotográfico propiedad de la autora. 


\section{CONCLUSIONES}

Muchos valores pueden asociarse con los bienes patrimoniales; aquellos que de algún modo los consideramos significativos y que serán justificaciones válidas para su protección y conservación, el desconocimiento de estos valores o la ausencia misma pueden llevar a los edificios al abandono y su destrucción. La puesta en valor de los sistemas constructivos de las Haciendas en Oaxaca, es hoy por hoy un valor de identidad, que lo distingue de algún modo con el resto de las Haciendas en México, no olvidando que cada una cumple con una actividad en particular, muy diferente. Pero la esencia misma, es decir, la forma como se conceptuaron cada una ellas varían unas de otras, de acuerdo a su presencia y el rol en el que participaron en una época determinada, siendo esto la preocupación por rescatar esa parte de la historia hacendaria oaxaqueña.

Fue interesante enlazar la parte histórica con la arquitectónica, formando una amalgama inimaginable de variantes y posibilidades que dieron origen y forma a una Arquitectura Hacendaria muy particular en Oaxaca, y no tan solo por su actividad, que fue un desarrollo de impacto social y económico en el siglo XVII y XVIII, en la Verde Antequera, sino la manera de edificar y conceptuar los espacios arquitectónicos que le dieron vida a estas actividades.

El desconocimiento de los inmuebles de las Haciendas y del vínculo que tienen unos con otros, es posible que impida entenderla como una unidad arquitectónica al servicio de la producción, para lograr este propósito fue necesario primero entender que la Arquitectura es un fenómeno cultural socio antropológico, producido en el área rural y que tiene connotaciones muy distintas a las que se encuentran edificadas cercanas a la ciudad, siendo la base los mismos materiales y sistemas constructivos, difiriendo en su resultante, y que gracias a estos materiales existe nuestra Arquitectura.
La investigación documental en archivos fue de gran utilidad ya que nos arrojó datos muy interesantes sobre la forma de construir muros gruesos y bajos, sencillez en la edificación, ausencia de vanos predominando grandes extensiones de muros, dando por resultado el uso de formas geométricas puras, pero sin perder de vista la unidad del conjunto mismo, sin tener una economía de medios en su época, se logra con el uso de los materiales naturales básicos que se encuentran a la mano, generando una riqueza visual de grandes proporciones, que corresponden a un entorno natural, formando parte del mismo.

Es evidente que, en estos programas arquitectónicos, hubo una correspondencia racional y económica, posible en la medida, entre la parte constructiva y la concepción arquitectónica. Los sistemas constructivos jugaron un papel vital, concebidos para cubrir claros considerables y permitir alturas fuera de lo común, tal es el caso del gavillero en esta ex Hacienda.

Son impresionantes la audacia y la inteligencia necesarias para llegar a resultados excepcionales cuya magnitud y eficacia fueron únicas. La admiración del hombre por el uso de estos sistemas y la forma permitió vencer las leyes de la gravedad, siendo estos edificios modestos, funcionales y cómodos para vivir, a pesar de encontrarse apartados de la capital oaxaqueña.

$Y$, para terminar, se reafirma que:

El México del ayer no es eterno... no dejemos que decaiga, y mucho menos que contribuyamos a su deterioro que sería la pérdida absoluta y ausencia total de nuestros valores, prácticamente el fin de la vida de nuestros monumentos...

Estamos a tiempo de cambiar de actitud y por lo menos dejar sembrada esta inquietud a quienes amany valoran nuestras tradiciones arquitectónicas, que hoy por hoy, aún se encuentran vivas. 


\section{REFERENCIAS}

Barbosa-Ramírez A. R. (1995). La Estructura Económica de la Nueva España (1519-1810). México. Editorial XXI. Novena Edición.

Carta Internacional para la Conservación y Restauración de Sitios y Monumentos (actualización de la Carta de Venecia) (1978). En documentos Internacionales 1982. Oaxaca, INAH, DEP.

Chevalier, F. (1999). La Formación de los Latifundios en México. Haciendas y Sociedad en los siglos XVI, XVII YXVIII. México. Fondo de Cultura Económica Tercera Edición.

Fernández I, Enfield G, \& Ohara S. (2004) jun-dic. Estrategias para el control del agua en Oaxaca Colonial. México. Estudios de Historia Novohispana. Instituto de Investigaciones Históricas No. 31, pp. 137-198.

García González E. (2011). Las Haciendas en México, México. Investigador del Instituto de Antropología Universidad Veracruzana-México.

Guerrero Baca L. F. (2002). El Tapial, una técnica constructiva ecológica. México. Anuario de Arquitectura Bioclimática, Limusa-UAM- Azcapotzalco México.

Icaza Lomelí, L. (s/a.). La Vara, México, (Material mecanográfico)

López Guzmán. R. (2007) Territorio, Poblamiento y Arquitectura. México en las Relaciones Geográficas de Felipe II. Granada España. Editorial Atrio.

Nickel, H. J. (1978). Morfología Social de la Hacienda Mexicana, Alemania. Ed. Franz Steiner Verlag.

Rocha Martínez R. (2013) mayo-agosto, La Vara. México. Boletín De Monumentos Históricos No.28 3era época. pp. 64-79. Instituto Nacional de Antropología e Historia.

Taylor, W. (1973). Haciendas coloniales en el valle de Oaxaca. Historia Mexicana, 23(2), 284-329. Recuperado de https://historiamexicana.colmex.mx/index.php/RHM/article/view/2959/2466 fecha de consulta 23 marzo 2018.

Taylor., W. (1998). Terratenientes y Campesinos en el Oaxaca Colonial. Oaxaca México. Instituto Oaxaqueño de las Culturas. Primera Edición.

Terán Bonilla., J. A. (1998). La construcción de las Haciendas en Tlaxcala., México. Instituto Nacional de Antropología e Historia., Primera re-impresión.

\section{Archivos y Bibliotecas}

(AEO)

(AGI)

(AGN)

(AGEO)

(AGPEO)

(AHMCO)

(AHTSJEO)

(ALCG)

(ANCO)
Archivo Eclesiástico de la Ciudad de Oaxaca

Archivo General de Indias en Sevilla España

Archivo General de la Nación en México

Archivo General del Estado de Oaxaca

Archivo General del Poder Ejecutivo del Estado de Oaxaca

Archivo Histórico Municipal de la Ciudad de Oaxaca "Manuel R. Palacios"

Archivo Histórico el Tribunal Superior Judicial del Estado de Oaxaca

Archivo Luis Castañeda Guzmán de Oaxaca

Archivo de Notarías Ciudad de Oaxaca 